\title{
A AVALIAÇÃO DE EVIDÊNCIAS EM SAÚDE PELA POPULAÇÃO
}

\author{
Maria Cristiane Barbosa Galvão \\ Universidade de São Paulo (USP) \\ mgalvao@usp.br \\ Fabio Carmona \\ Universidade de São Paulo (USP) \\ carmona@usp.br \\ Ivan Luiz Marques Ricarte \\ Universidade Estadual de Campinas (UNICAMP) \\ ricarte@unicamp.br
}

\begin{abstract}
Resumo
Objetivou-se verificar como a população avalia as evidências sobre a saúde de crianças e adolescentes. Para atingir esse objetivo, foram disseminadas evidências em saúde, produzidas com linguagem simples, focadas nos falantes da língua portuguesa, em uma plataforma tecnológica e nas mídias sociais. Foram analisadas 113 avaliações de evidências realizadas por enquete, em plataforma tecnológica, usando questionário estruturado, e, 136 avaliações provenientes de comentários livres registrados em mídias sociais. Percebeu-se que, nas mídias sociais, a população avalia as evidências dicotomicamente, por concordância ou discordância, considerando experiências pessoais. Já as avaliações coletadas por plataforma tecnológica empregando questionário estruturado possui menos adesão da população, porém são mais detalhadas. Observou-se que o público que mais avalia a informação são as mulheres. Conclui-se que é necessário fazer com que as evidências em saúde sejam avaliadas por outros segmentos da população, preferencialmente empregando instrumentos formais de avaliação, por serem mais detalhados.
\end{abstract}

Palavras-chave: Avaliação da informação. Evidência em saúde. População. Mídias sociais. Estudo misto.

\section{EVALUATION OF HEALTH EVIDENCE BY THE POPULATION}

\begin{abstract}
The objective was to verify how the population evaluates evidence on the health of children and adolescents. To achieve this goal, health evidence was produced, employing simple language, focusing on Portuguese speakers, on a technological platform and on social media. 113 assessments of evidence using a technology-based structured survey were analyzed, as well as 136 assessments from free comments registered on social media. It was noticed that, in social media, the population evaluates the evidence dichotomously, by agreement or disagreement, considering personal experiences. On the other hand, assessments collected by a technological platform using a structured survey have less population adherence, but they are more detailed. It was observed that the public that most evaluates the information is composed by women. It is concluded that it is necessary to make health evidence be evaluated by other segments of the population, preferably employing formal assessment instruments, as they are more detailed.
\end{abstract}

Keywords: Information assessment. Health evidence. Population. Social Media. Mixed study. 


\section{INTRODUÇÃO}

As pesquisas realizadas na área da saúde produzem um volume substancial de dados e informações. Apenas em 2018, foram indexados na base de dados PubMed mais de 1,3 milhão de novos artigos, ou seja, uma média superior a 150 novos estudos publicados por hora. Selecionar, dentre esses estudos, aqueles que possam ser implementados no contexto clínico é o desafio do processo de trabalho conhecido genericamente pelo termo "prática em saúde baseada em evidência". Neste âmbito, "evidência" denomina o resultado de pesquisa científica que pode ser utilizado para aperfeiçoar a prática profissional, as decisões, a prevenção, as condições e os resultados de saúde, bem como para aumentar a resiliência ou confiança de todos os envolvidos no campo da saúde, incluindo pacientes, população em geral, gestores e demais profissionais.

A seleção, síntese e disseminação de evidências para profissionais da saúde é um processo bem estabelecido internacionalmente, com processos e métricas de avaliação consolidados como McMaster Online Rating of Evidence - MORE (HAYNES et al., 2006), Level of Evidence - LOE (CENTRE, 2016), Number Needed to Benefit from Information - NNBI (PLUYE et al., 2013) e Clinical Relevance of Information Index - CRII (GALVAO et al., 2013). Contudo, é preciso esclarecer que a disseminação de evidências para profissionais da saúde difere da disseminação de evidências para a população leiga. Esta diferença ocorre, em grande parte, porque os profissionais da saúde adquirem em alguma medida, durante sua formação acadêmica e profissional, algumas competências informacionais, competências tecnológicas e algum conhecimento sobre a linguagem e os métodos científicos de modo que estão mais habilitados para a compreensão das pesquisas científicas e das evidências nelas apresentadas. Já a população nem sempre possui condições para a compreensão da linguagem científica, fato que demanda estratégias de disseminação de evidências que empreguem linguagem simples (WORLD, 2019).

Entende-se por linguagem simples aquela que permite que o público compreenda a mensagem pela primeira vez que a lê ou a ouve. A escrita em linguagem simples é concisa, bem organizada e segue um conjunto de práticas que facilitam a compreensão da mensagem ao empregar, por exemplo, voz direta e ativa, frases curtas, palavras cotidianas e recursos de design que facilitam a leitura pela população que possui baixa competência informacional. Um documento emprega linguagem simples quando o público pode encontrar a informação que precisa, consegue compreender a informação e consegue usar a informação para atender às suas necessidades (STABLEFORD; METTGER, 2016; UNITED, s.d.). 
Adicionalmente, quando se fala em disseminação de evidências para a população, além do uso da linguagem simples, é preciso pensar nos canais de comunicação. Nesse sentido, o uso de plataformas tecnológicas e mídias sociais de baixo custo tem ganhado espaço e tem sido recomendado por instituições como a Federação Internacional de Associações de Bibliotecas (IFLA) e a Organização Mundial da Saúde (WORLD, 2012). A IFLA esclarece, por exemplo, que a transição de um mundo de publicação impressa para um em que muitas das principais fontes de informação de saúde são principalmente digitais demanda, evidentemente, de novas formas de disseminação de informações e dados de saúde que considerem a informação certa e confiável para os diferentes tipos de públicos, empregando os veículos mais adequados para a comunicação (INTERNATIONAL, 2017).

Vários estudos internacionais foram realizados sobre a disseminação de informações em saúde na Web e as mídias sociais com foco na população leiga.

Em estudo realizado em um hospital pediátrico australiano, Benedicta, Caldwell e Scott (2019) constataram que mães e pais complementam as informações disponibilizadas pelos profissionais da saúde com consultas a fontes na Web, havendo aqueles que preferem consultar a informação online em vez de discutir com os profissionais, o que pode produzir efeitos adversos. Um estudo com mães de crianças de até seis meses de idade, realizado nos Estados Unidos, mostrou que as mães buscam cotidianamente informações sobre as condições de saúde dos filhos na Web e em mídias sociais, chegando a confiar mais nessas fontes que em parentes, amigos e até mesmo nos profissionais de saúde (MOON et al., 2019).

Em estudo com adolescentes de 13 a 18 anos, Freeman et al. (2018) observaram que os jovens também usam a Web como fonte de informação em saúde, mas que nesse público a avaliação sobre a qualidade da informação é muitas vezes instintiva, carecendo de critérios mais sofisticados para atestar a credibilidade na fonte.

Kim e Choi (2018) observaram que a população julga que a informação tem maior credibilidade quando é objetiva e compreensível. Já Sbaffi e Rowley (2017) destacam que a maior parte das pesquisas atuais sobre a credibilidade da informação em saúde na Web são de caráter quantitativo, porém com resultados não conclusivos, havendo uma necessidade de realizar mais pesquisas qualitativas sobre o tema.

De forma complementar aos estudos já realizados, o presente estudo teve por objetivo verificar como a população avalia as evidências sobre a saúde de crianças e adolescentes disseminadas em plataformas tecnológicas e nas mídias sociais. Para atingir esse objetivo foram disseminadas evidências em saúde, produzidas com linguagem simples, focando os falantes da 
língua portuguesa, em uma plataforma tecnológica e nas mídias sociais, como será detalhado na próxima seção.

\section{MÉTODOS}

Na dimensão teórica, esta pesquisa seguiu a abordagem de estudo misto sequencial explanatório. A pesquisa com métodos mistos combina os métodos de pesquisa qualitativos e quantitativos e tem por objetivo generalizar os resultados qualitativos, ou aprofundar a compreensão dos resultados quantitativos, ou corroborar os resultados qualitativos ou quantitativos (JOHNSON; ONWUEGBUZIE; TURNER, 2007; PLUYE, 2012). Existem várias tipologias de estudos mistos. O estudo sequencial explanatório se inicia por uma etapa quantitativa e é seguida por uma etapa qualitativa. Nesta abordagem, os resultados qualitativos são empregados para melhor compreensão dos resultados quantitativos (GALVAO; PLUYE; RICARTE, 2018).

Na dimensão empírica, esta pesquisa contemplou quatro etapas.

$\mathrm{Na}$ primeira etapa, foram selecionadas as temáticas das evidências que seriam disseminadas. Dada a experiência dos autores, optou-se por temas relacionados ao cotidiano de crianças e adolescentes brasileiros. Além disso, foram consideradas as dúvidas sobre saúde enviadas pela população por meio dos diferentes canais de comunicação do projeto.

$\mathrm{Na}$ segunda etapa, as temáticas selecionadas foram transformadas em questões padronizadas. Para cada questão foi elaborada uma resposta curta com até 160 caracteres, para leitura rápida, e uma resposta longa, com até 500 palavras, para leitores que queiram informação mais detalhada. Para a criação das questões padronizadas e elaboração das respostas, dois dos autores (MCBG, FC) treinaram profissionais de saúde e estudantes dos campos da saúde, perfazendo um total de 14 pessoas envolvidas na produção de 433 resumos de evidências que foram disseminados para a população, entre 31 de março de 2016 a 10 de junho de 2019. Para a construção desses resumos foram consultadas bases bibliográficas e de evidência em saúde como: UpToDate, Dynamed, Access Medicine, Pubmed via Pico e ScIELOo. Como várias bases disponibilizam informação apenas em língua inglesa, buscou-se, para cada caso, realizar as adequações culturais para melhor compreensão do conteúdo em língua portuguesa. Cada resumo de evidência foi revisado por dois pesquisadores, sendo um médico (FC) e um bibliotecário especializado em informação em saúde (MCBG). No processo de revisão, foram verificados a tradução correta, a adequação da linguagem para a população, a adequação da informação no contexto da língua portuguesa, a adequação das referências e a isenção da 
mensagem. Caso um revisor tivesse algum tipo de apontamento, a questão e a resposta voltavam para o processo de elaboração. Logo, as informações só foram publicadas nas plataformas do projeto se os dois revisores concordaram com o conteúdo da questão e da resposta. O processo de produção e revisão das evidências em português foi apoiado pela plataforma Research Electronic Data Capture (REDCap), desenvolvido pela Vanderbilt University, nos Estados Unidos (HARRIS et al., 2019).

$\mathrm{Na}$ terceira etapa, cada evidência foi enviada para a plataforma de Blogger, Facebook e Twitter. Cada evidência disseminada disponibilizava um link para a enquete de avaliação da evidência na plataforma REDCap. Ao clicar neste link, a população tinha acesso ao instrumento estruturado IAM4All (PLUYE et al., 2014), desenvolvido pela McGill University, no Canadá, e traduzido por estes autores para uso no Brasil. Esse instrumento captura a percepção da população sobre uma evidência em saúde considerando aspectos como a relevância da informação, facilidade de compreensão, intenção de uso e benefício esperado. A população também tinha a possibilidade de não clicar no link de avaliação e deixar seus comentários livres nas mídias sociais.

$\mathrm{Na}$ quarta etapa, os pesquisadores reuniram e sistematizaram as avaliações recebidas por cada evidência por meio da plataforma REDCap e por meio de comentários livres nas mídias sociais. As avaliações registradas pela população no REDCap foram analisadas quantitativamente por meio de estatística descritiva. Já os comentários públicos registrados nas mídias sociais foram analisados qualitativamente. Para tanto, foram anonimizados, receberam uma identificação numérica e foram analisados tematicamente e independentemente por dois autores (MCBG, ILMR). A análise independente por dois pesquisadores é uma maneira de reduzir efeitos relacionados à subjetividade e à interpretação dos comentários. Para a avaliação final, as análises independentes para cada comentário foram tabuladas e consolidadas em comum acordo. Das 433 evidências disseminadas, a etapa qualitativa selecionou os comentários sobre três evidências. 


\section{RESULTADOS}

Nesta seção, serão apresentados os resultados quantitativos, em seguida, os resultados qualitativos, e, finalmente, a análise de como os dados qualitativos podem ou não complementar os resultados quantitativos.

\subsection{Resultados quantitativos}

A etapa quantitativa da pesquisa consistiu em enquete sobre opinião do público sobre as evidências disseminadas. Por meio da enquete, foram obtidas 113 avaliações no período de 40 meses, de maio de 2016 a setembro de 2019; destas, foram consideradas para esta etapa da pesquisa as avaliações que traziam informações suficientemente completas. Atenderam a este critério 90 avaliações sobre 80 evidências das 433 evidências disseminadas.

Além de avaliar evidência, os respondentes podiam voluntariamente registrar, na enquete, informação sobre seu perfil demográfico. Dos 90 respondentes, 53 optaram por fornecer dados demográficos. Dentre aqueles que declararam as informações sobre a idade e, opcionalmente, sobre o sexo, a maioria foi composta por mulheres $(n=41,77,4 \%)$ e a faixa etária foi de 12 a 68 anos (média 40,2 anos), sendo o grupo etário com maior quantidade de respondentes aquele com idades entre 31 e 34 anos $(n=14,26,4 \%)$. O Gráfico 1 sintetiza o perfil demográfico dos respondentes.

Gráfico 1 - Perfil demográfico dos respondentes da enquete de avaliação da evidência: idade e sexo.

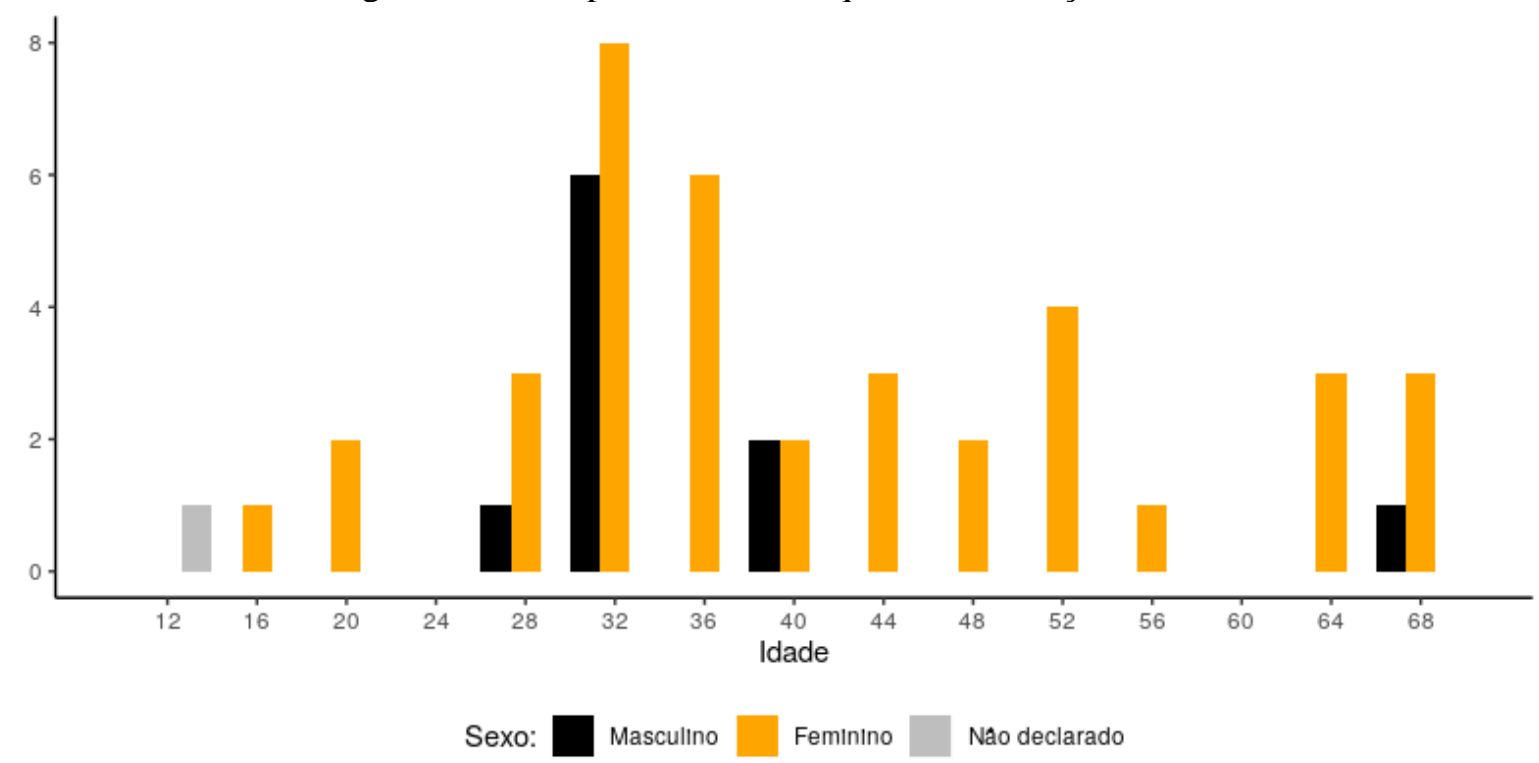

Fonte: elaborado pelos autores (2019). 
Em relação à escolaridade, a maioria dos respondentes declarou ter a graduação completa $(n=21,39,6 \%)$, seguido pelos respondentes com ensino médio completo $(n=16,30,2 \%)$, mestrado $(n=5,9,4 \%)$, ensino fundamental incompleto $(n=5,9,4 \%)$, técnico profissionalizante $(\mathrm{n}=3,5,7 \%)$, doutorado $(\mathrm{n}=1,1,9 \%)$ e ensino fundamental completo $(\mathrm{n}=1,1,9 \%)$; um respondente preferiu não declarar a escolaridade. Vinte participantes $(37,7 \%)$ declararam ser profissionais cujo trabalho envolve crianças ou adolescentes. No que diz respeito à renda mensal familiar, a maior parte declarou receber entre 2 e 5 salários mínimos ( $\mathrm{n}=21,39,6 \%)$, seguidos por aqueles com renda familiar mensal entre 5 e 10 salários (n=10,18,9\%), 1 salário $(n=6,11,3 \%)$, sem rendimentos $(n=4,7,5 \%)$ e com rendimentos entre 10 e 20 salários $(n=1$, $1,9 \%)$. Onze participantes optaram por não declarar sua renda mensal.

O primeiro aspecto sobre a disseminação avaliado pelos respondentes foi sobre a relevância da evidência disseminada para a pessoa, por meio da questão "Esta informação é relevante?” (Gráfico 2). Mais de 90\% dos respondentes consideraram as evidências relevantes, sendo a opção mais frequente "Muito relevante (Atendeu minha expectativa)" (n=59, 65,6\%), seguida por "Relevante" (n=24, 26,7\%). Entre os que questionaram a relevância da questão, uma avaliação $(1,1 \%)$ considerou a evidência "Pouco relevante" e 3 avaliações $(3,3 \%)$ consideraram a evidência "Muito pouco relevante (Não atendeu minha expectativa)". A evidência considerada pouco relevante foi "O que causa micose na virilha?" e as consideradas muito pouco relevantes foram “O que é pré-diabetes?" e "O que é fissura anal?". Três respondentes não selecionaram nenhuma opção para esse item da avaliação.

Gráfico 2 - Respostas à questão "Esta informação é relevante?"

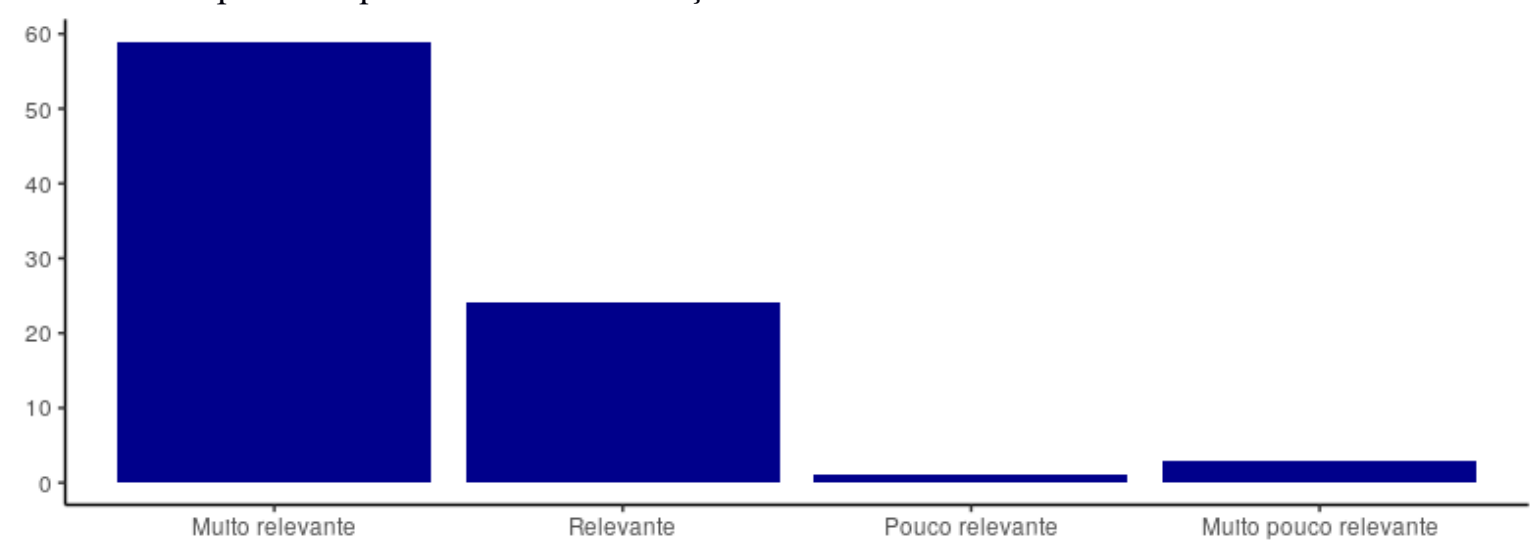

Fonte: elaborado pelos autores (2019).

Outro aspecto avaliado foi se a informação era compreensível (Gráfico 3). Também nesse aspecto a avaliação foi positiva, obtendo quase a totalidade $(97,8 \%)$ dos respondentes. A maior parte dos respondentes indicou que "Eu compreendi muito bem (Eu compreendi tudo)" (n=61, 
$67,8 \%)$ e "Eu compreendi bem" ( $n=27,30,0 \%)$. Apenas um respondente $(1,1 \%)$ indicou que "Eu compreendi mal”, relacionado à evidência "O que é fissura anal?". Nenhum respondente escolheu a opção "Eu compreendi muito mal (Eu não compreendi muita coisa)" e um respondente optou por não responder este item da avaliação.

Gráfico 3 - Respostas à questão "Você entendeu esta informação?"

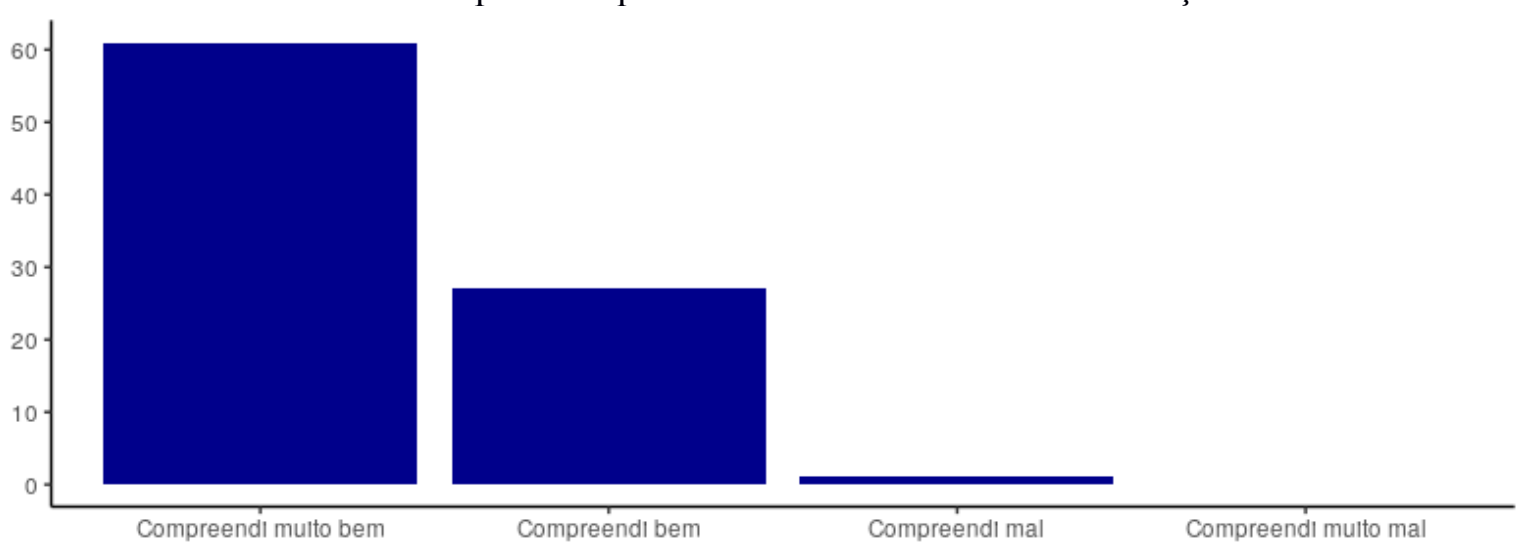

Fonte: elaborado pelos autores (2019).

O item seguinte da avaliação foi “O que você acha desta informação?”. Para este item mais de uma opção poderia ser assinalada (Gráfico 4). As respostas obtidas foram relacionadas, em sua maioria, a aspectos positivos: "Esta informação me ensinou algo novo" ( $n=47,52,2 \%)$, "Esta informação me incentivou a aprender mais sobre o assunto" (n=24, 26,7\%), "Esta informação confirmou que eu faço ou fiz a coisa certa" (n=17, 18,9\%), "Esta informação me lembrou de algo que eu já sabia" $(n=12,13,3 \%)$ e "Esta informação me tranquilizou" (n=10, 11,1\%). As opções associadas a aspectos negativos foram pouco assinaladas: "Eu acho que há um problema com esta informação" ( $n=3,3,3 \%)$, "Não estou de acordo com esta informação" $(n=1,1,1 \%)$ e "Esta informação pode gerar consequências negativas" ( $n=1,1,1 \%)$. 


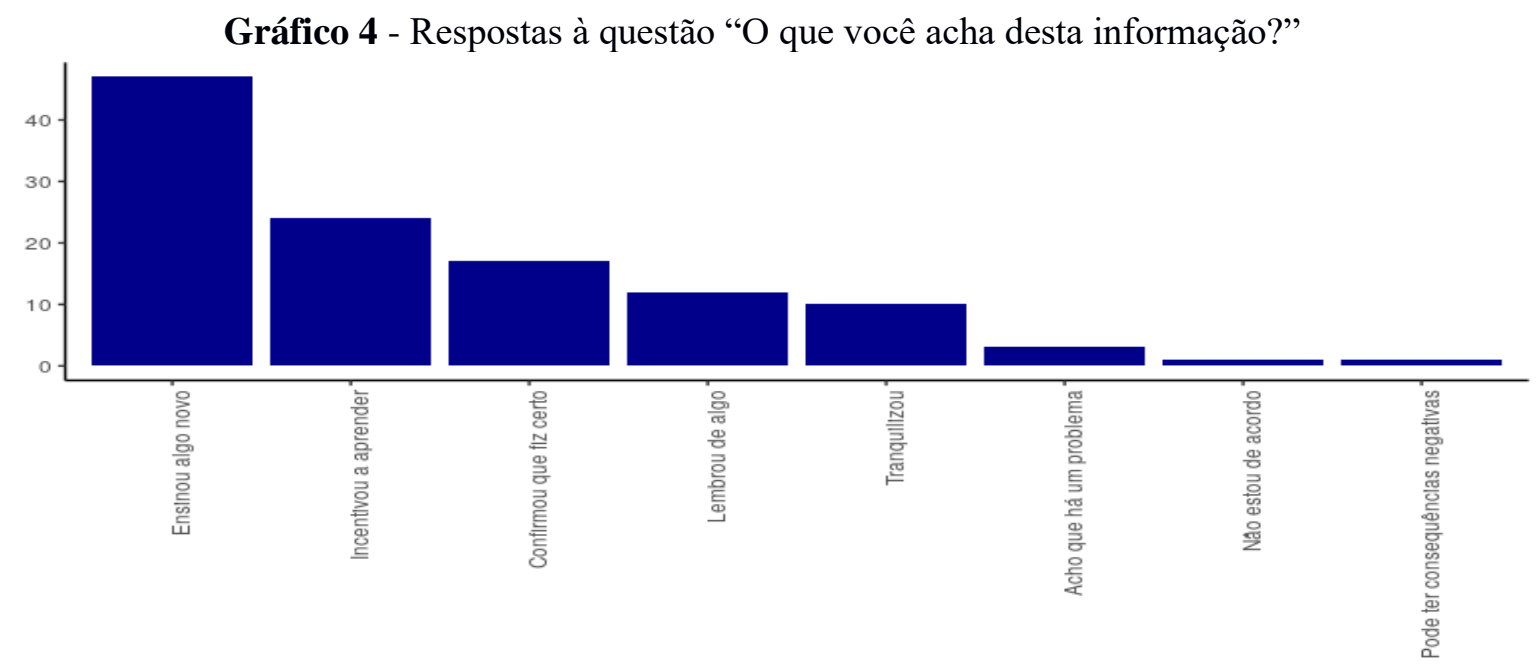

Fonte: elaborado pelos autores (2019).

Os participantes da pesquisa foram convidados a responder se usariam ou não a evidência e, se sim, em qual papel social (pais, avós, outros familiares, amigos ou vizinhos, profissionais de saúde). Adicionalmente, se o respondente fosse o pai ou a mãe de uma criança ou adolescente, seria convidado a responder sobre como usaria a evidência e qual o benefício esperado. Para a questão "Você usará esta informação?”, a grande maioria (n=79, 87,8\%) afirmou que sim. Apenas $4(4,4 \%)$ afirmaram que não fariam uso da informação, enquanto 7 respondentes não assinalaram nenhuma opção.

Entre os que responderam que usariam a evidência, a maioria estavam no papel de "Mãe ou pai de uma criança ou adolescente" (n=34, 37,8\%) ou de "Profissional da saúde que assiste criança ou adolescente" ( $n=18,20,0 \%)$, seguidos por "Membro de uma família onde há uma criança ou adolescente" ( $\mathrm{n}=9,10 \%)$, “Amigo, vizinho ou membro de uma comunidade onde há uma criança ou adolescente" ( $n=8,8,9 \%)$ e "Avó ou avô de uma criança ou adolescente" (n=4, 4,4\%), como apresentado no Gráfico 5. A opção "Nenhuma das opções acima" foi assinalada por 16 respondentes $(17,8 \%)$, que declararam que usariam a informação para a sua própria saúde, no contexto profissional ou para fins escolares. Deve-se observar que essas opções não eram exclusivas, pois um respondente poderia utilizar a mesma evidência em diferentes situações. 
Gráfico 5 - Respostas ao item "Você usará esta informação em qual papel social"

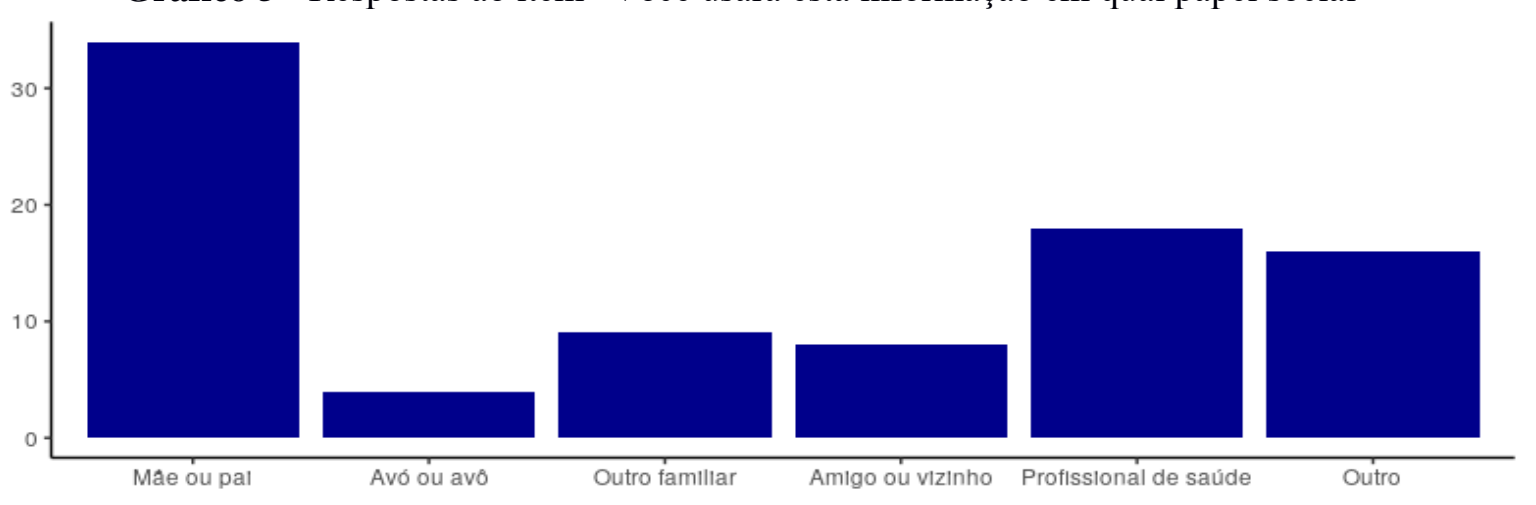

Fonte: elaborado pelos autores (2019).

Os respondentes que informaram estar na função de mãe ou pai $(n=34)$ disseram, em sua maioria, que "Esta informação me ajudará a compreender melhor" ( $n=24,70,6 \%$ dos pais) e que "Usarei esta informação para conversar com alguém" ( $n=8,23,5 \%)$, como pode-se observar no Gráfico 6. As outras opções selecionadas foram "Eu não sabia o que fazer, e esta informação me convenceu a fazer algo" $(\mathrm{n}=4,11,8 \%)$, "Usarei esta informação para fazer as coisas de outra forma" ( $n=3,8,8 \%)$ e "Eu sabia o que fazer, e esta informação me convenceu a fazer alguma coisa" $(n=1,2,9 \%)$. Aqui também deve-se observar que a mesma evidência pode ter mais de um uso e, portanto, um respondente poderia assinalar mais de uma opção.

Gráfico 6 - Respostas à questão “Como você usará esta informação?”, respondida por mães ou pais

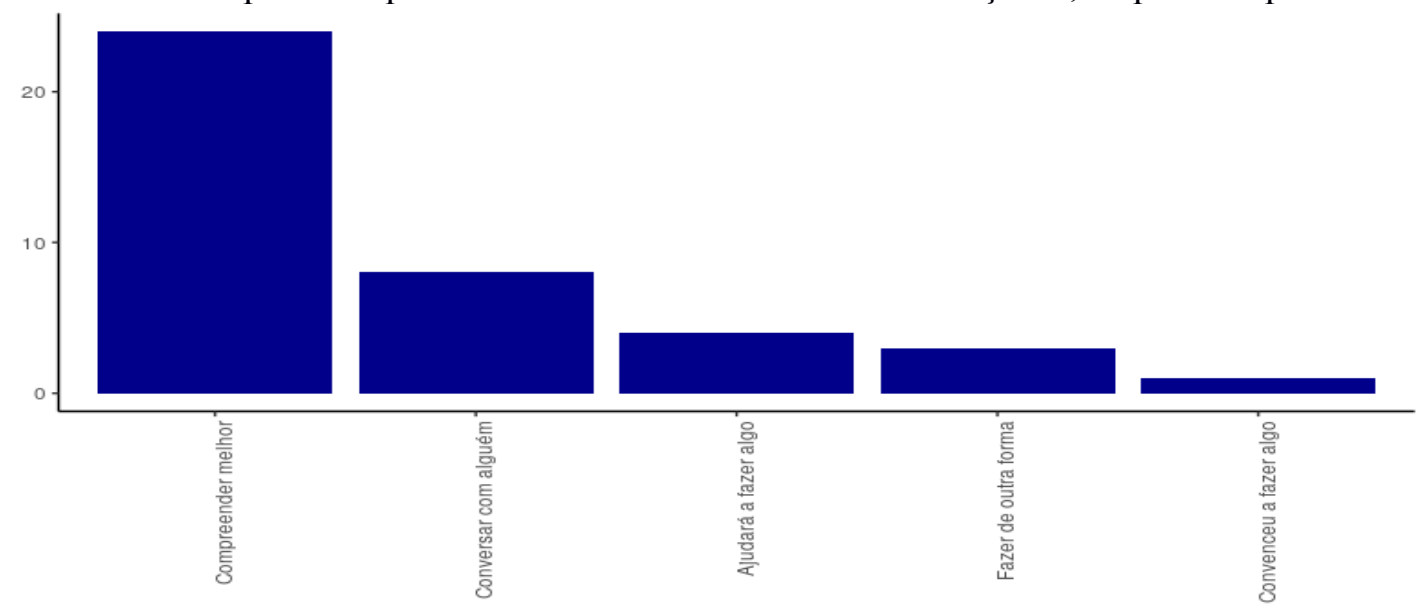

Fonte: elaborado pelos autores (2019).

Em relação aos benefícios esperados por esse mesmo grupo de pais ao usar a evidência, a maioria assinalou que "Esta informação me ajudará a melhorar o bem-estar ou a saúde do meu filho" (n=20, 58,8\%) e que "Esta informação me ajudará a prevenir um problema ou impedir que ele se agrave" $(\mathrm{n}=11,32,4 \%)$, como pode-se observar no Gráfico 7. As outras opções assinaladas foram, todas com 4 respondentes $(11,8 \%)$, "Esta informação me ajudará a 
ser menos preocupado ou ansioso", "Esta informação me ajudará a gerenciar um problema", "Eu estarei melhor preparado para discutir com alguém" e "Eu terei mais confiança em mim para decidir o que fazer com outra pessoa". Por fim, apenas um respondente $(2,9 \%)$ assinalou “Eu não prevejo qualquer benefício". Mais uma vez, as opções não eram exclusivas e mais de um benefício poderia ser assinalado pela mãe ou pai.

Gráfico 7 - Respostas à questão "Usando esta informação, você espera benefícios para você e seu filho?”, respondida por mães ou pais

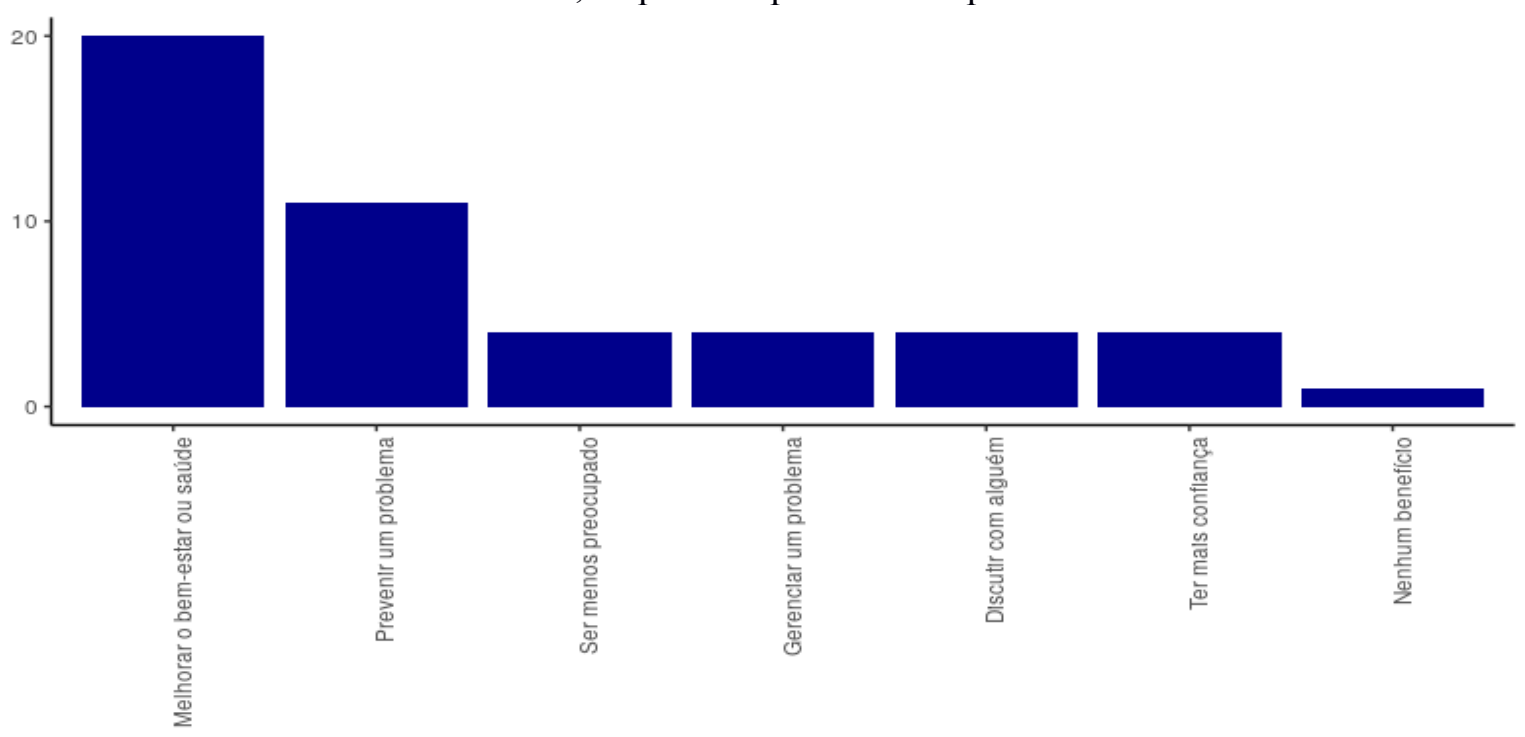

Fonte: elaborado pelos autores (2019).

\subsection{Resultados qualitativos}

Na fase qualitativa, foram considerados os comentários sobre três evidências emitidos pela população nas mídias sociais. Tais evidências abordavam: o uso de chupeta por bebês (evidência 1); a manutenção de irmãos gêmeos na mesma sala de aula (evidência 2); e os benefícios das fraldas de pano para a saúde do bebê (evidência 3). Foram contabilizados nesta etapa 136 comentários, que foram analisados de forma independente por dois dos autores (MCGB, ILMR). Após consolidação das análises, emanaram cinco categorias de manifestações da população sobre as evidências disseminadas: 1) concorda com a evidência; 2) discorda da evidência; 3) tem ressalvas em relação à evidência; 4) indica a evidência para outra pessoa; 5) a evidência gerou novas dúvidas.

A primeira evidência selecionada discorreu sobre o uso de chupeta por bebês e foi disseminada nas mídias sociais no dia 6 de junho de 2018. 


\section{Evidência 1}

Questão: Será que usar chupeta faz mal ao bebê??

Resposta curta: Usar chupetas está associado a deformidades na face e aumento de doenças infecciosas.

Resposta longa: $O$ uso de chupetas e o hábito de chupar o dedo estão associados a deformidades nos ossos da face, nos dentes e a outros problemas de saúde. O principal risco relacionado a uso de chupetas é a má-oclusão dentária, o que quer dizer que os dentes ficam tortos e não se encaixam. A possibilidade de ocorrerem deformidades caso a criança permaneça usando chupetas após os três anos de idade é grande. Mas o risco de deformidades na face também se relaciona a quanto tempo a criança passa chupando a chupeta. As deformidades na face ocorrem nos dentes e nos ossos da face. As deformidades podem ocorrer também em dentes permanentes. A má-oclusão dentária acaba deixando os dentes levantados. Os dentes levantados não são mais protegidos pela boca. Dentes que não são protegidos pela boca tem maior risco de quebrarem em uma batida da cabeça. As chupetas ortodônticas não eliminam o risco de má-oclusão e funcionam da mesma forma que as comuns. Além disto, o uso da chupeta aumenta o risco para infecções de ouvido e de garganta. $O$ uso da chupeta também pode provocar a parada precoce da amamentação no seio materno. Crianças que chupam chupeta têm menor chance de permanecer com o hábito após os 3 anos de idade do que aquelas que chupam o dedo. A chupeta não aumenta o número de cáries nos primeiros anos da criança, se realizada a higiene bucal corretamente.

Referência: UpToDate. Oral habits and orofacial development in children. Informação atualizada em fev. 2017. Disponível em: https://www.uptodate.com/. Acesso em: $12 \mathrm{dez}$. 2017.

A evidência 1 gerou 52 comentários (rotulados de $\mathrm{C} 1$ a C52) emitidos todos por mulheres, dos quais 26 manifestaram discordância com a evidência em saúde, 16 manifestaram concordância com a evidência, 4 apresentaram ressalvas com a evidência, 6 apresentaram outra questão não abordada pela evidência apresentada. Foram considerados de discordância, comentários como: C23 "Sim, tem que dar a chupeta. Eu dei pra minhas 2 filhas. Elas adoravam a chupeta. kkkk"; C6 "Minha filha parou com a chupeta aos 7 anos... não deu tanto trabalho, não!!!”; C15 “Ai Tata acho tão lindinho kkkk ah e anestésico tbm kkkk”. Foram considerados de concordância, comentários semelhantes a: C10 "Não é questão de achar, é ciência! Chupeta é plástico, pra que dar plástico pro seu filho ficar sugando? Chupeta afeta a respiração, fala, dentição e gera diversas instabilidades emocionais na criança. São danos para uma vida inteira que os pais ignoram."; C32 "Problema de dentição não se restringe a dentição torta até pq isso em maioria é genético devido ao tamanho dos dentes em relação ao espaço disponível, entre outros problemas. O problema decorrente da chupeta é na estrutura. Consulte um dentista". Foram considerados com ressalvas, comentários como: C4 "Acho que há casos e casos. Como não consegui amamentar a chupeta me ajudou muito. A sucção acalma demais os bebês. Agora 
com 2 anos consegui tirar a chupeta de forma bem tranquila e não traumática."; C14 "Graças a Deus, meu filho largou antes dos 2 anos. Realmente, é horrível criança com chupeta, mas tem determinados momentos que faz uma faltaaa uma pepeta e o paninho kkkk". Foram considerados como outra questão, comentários como: C19 "Meu filho de 7 anos não chupou chupeta e está com os dentes nascendo tortos!!! E aí? Nesse caso o que pode ter sido?”; C44 “Cada mãe sabe o que é melhor para o seu filho e para sua própria sanidade. O meu eu não dei chupeta. Mas não critico quem dá."

A segunda evidência selecionada discorreu a manutenção de irmãos gêmeos na mesma sala de aula e foi disseminada nas mídias sociais no dia 23 de maio de 2018.

\section{Evidência 2 \\ Questão: Gêmeos devem estudar na mesma sala de aula ou em salas diferentes?}

Resposta curta: Gêmeos que estudam na mesma sala de aula possuem menos problemas comportamentais na escola.

Resposta longa: Os problemas comportamentais das crianças ocorrem em função de influências genéticas e ambientais. Uma influência ambiental potencialmente importante é o ambiente da sala de aula. Muitas escolas decidem arbitrariamente manter irmãos gêmeos separados e outras permitem que os pais decidam se querem manter seus filhos gêmeos na mesma sala de aula ou não. Assim, uma grande dúvida é se a separação de gêmeos em salas de aula diferentes é a decisão mais adequada. Para analisar essa questão, um estudo com 1941 pares de gêmeos monozigóticos na Inglaterra, observou o comportamento escolar de irmãos gêmeos nos primeiros 7 anos de vida que estudavam na mesma sala, e também, gêmeos que estudavam em salas separadas. Observou-se, então, que gêmeos que estudam na mesma sala de aula desenvolvem comportamentos semelhantes e possuem menos problemas comportamentais na escola. Já os gêmeos que são colocados em salas de aula separadas têm seus problemas de comportamento agravados. Assim, há razões para considerar que os pais devem ter a permissão para manter seus filhos gêmeos na mesma sala de aula.

Referência: DiLalla, L. et al. The effect of classroom environment on problem behaviors: a twin study. Journal of School Psychology, v.46, n.2, p. 107-128, 2008.

A evidência 2 gerou 79 comentários (rotulados de G1 a G79) emitidos por mulheres, dos quais 29 manifestaram discordância com a evidência em saúde, 43 manifestaram concordância com a evidência, 2 apresentaram ressalvas com a evidência, 2 apresentaram outra questão não abordada pela evidência apresentada. Foram considerados de discordância, comentários como: G3 "Separados com certeza."; G38 "Salas separadas porque sempre tem um que depende mais do outro. Eu tenho gêmeos eles estudam separados desde o terceiro ano. Achei que valeu a pena separá-los."; G61 "Separados para se tornarem independentes um do outro, apesar de terem nascidos juntos são cada um por si, se eu tivesse gêmeos faria questão disso \#minhaopiniao". 
Foram considerados de concordância, comentários semelhantes a: G66 "Sou gêmea e a favor de sempre estudar junto... Estudei até o final do ensino médio com minha irmã e isso foi ótimo.”; G10 "Os meus gêmeos estudam juntos, nunca se separaram. Eles têm 9 anos." Foram considerados com ressalvas, comentários como: G27 "Sou gêmea, e sempre estudamos na mesma sala para nós foi ótimo, tanto em comportamento, quanto nos estudos... mas deve ser analisado cada caso individual." Foram considerados com outra questão, comentários como: G63 "Deve seguir de acordo com a disponibilidade das salas assim como qualquer outro irmão". A evidência 3 discorreu sobre o uso de fraldas de pano e foi disseminada nas mídias sociais no dia 28 de agosto de 2017.

Evidência 3

Questão: Existem diferenças entre as fraldas descartáveis e as fraldas de pano?

Resposta curta: Fraldas de pano são econômicas e esquentam menos os genitais dos bebês, sendo uma alternativa ao uso de fraldas descartáveis.

Resposta longa: Um fator que contribuiu muito para facilitar os cuidados com a higiene em crianças foi a popularização do uso de fraldas descartáveis. Nos anos 40, em função da escassez do algodão, provocada pela guerra, foi lançada na Suécia a primeira fralda descartável no mundo. A fralda descartável, nos anos 50, era um artigo luxuoso, sendo usada apenas em ocasiões especiais. Seu alto custo não permitia atingir a maioria da população, e sua distribuição estava limitada a poucos países. Nos anos 60, a indústria de fraldas descartáveis se desenvolveu bastante, pois começou a compreender as necessidades das mães. Com a disseminação das fraldas descartáveis, algumas famílias, mesmo sem ter condições de comprar, demonstram muita ansiedade para adquiri-las $e$ usá-las no seu bebê. Mesmo sabendo que a fralda descartável é um produto caro, não se deve usar a mesma fralda descartável durante todo o dia, pois isso pode provocar assaduras, e é muito desconfortável para a criança. Assim, é necessário verificar a fralda com frequência para avaliar o quanto a criança está fazendo de xixi e verificar se há a presença de cocô. Havendo xixi em grande quantidade ou cocô, a fralda deve ser trocada. Contudo, o tamanho da criança também interfere nesta troca, pois com o crescimento da criança as eliminações de xixi passam a ser maiores. Logo, a quantidade de fraldas necessárias para atender uma criança pode aumentar com o tempo. Uma alternativa para aquelas mães que são preocupadas com questões de meio ambiente ou que querem economizar na compra das fraldas descartáveis é aderir ao uso de fraldas de pano com capas protetoras. $O$ uso destas fraldas poupa espaço nos aterros sanitários, economiza recursos naturais, são econômicas, utiliza menor quantidade de substâncias químicas, $e$ esquenta menos os genitais dos bebês. A quantidade de fraldas de pano necessária para atender o bebê varia de acordo com a rotina da família e de quantas vezes por semana é possível lavá-las. Deve-se avaliar o seu tempo de secagem de acordo com as características de moradia da família.

Referência: [Dynamed]. Diaper dermatitis. Informação atualizada em dez. de 2015. Disponível em:http://portalsaude.saude.gov.br/index.php/oministerio/principal/periodicos. Acesso em: 15ago. 2016. 
Access Medicine [Internet]. Chang, Mary Wu. Neonatal, pediatric, and adolescent dermatology. In: Hay, W.W. Jr., et al. eds. Fitzpatrick's Dermatology in General Medicine. 8ed. New York: McGraw-Hill, 2012. Disponível em: http://portalsaude.saude.gov.br/index.php/o-ministerio/principal/periodicos. Acesso em: 15 ago. 2016.

A evidência 3 gerou 5 comentários (rotulados de F1 a F5) emitidos todos por mulheres, dos quais 4 manifestaram discordância com a evidência em saúde e 1 levantou outra questão não abordada pela evidência apresentada. Foram considerados de discordância, comentários como: F1 "Pelo amor de Deus!! Voltar às fraldas de pano é um retrocesso! Será que também farão campanha contra o absorvente feminino? Afinal, a função é quase a mesma. Aff me poupem dessa demagogia"; F2 "Usei, no meu primeiro filho, as fraldas de pano. Posso dizer que foi uma tortura. Não segura o xixi do bebê e tinha que ficar trocando toda hora, para não assar a pele do bebê. Não recomendo. É minha opinião".

Primeiramente, chama a atenção dos comentários serem emitidos por mulheres em sua totalidade. Isso pode ser um indício de que os homens não tenham tanto interesse na temática crianças e adolescentes ou que as informações produzidas são escritas em linguagem e formato não adequados para o público masculino.

Em relação aos comentários recebidos, as mulheres que produziram esses comentários refutam ou confirmam a evidência a partir de suas experiências de vida, não havendo talvez a compreensão de que a ciência se guia, fortemente, por estudos de grupos e métricas estatísticas e não por casos isolados. Em outras palavras, elas colocam em pé de igualdade seu conhecimento pessoal e o conhecimento científico. Por um lado, isto parece ser algo positivo, pois as mulheres não parecem aceitar as informações em saúde passivamente. Elas pensam e refletem sobre o seu caso. Por outro lado, ao valorizar apenas a experiência de vida podem perder a oportunidade que a ciência oferece de seguirem um caminho diferente, o que pode inclusive evitar maiores problemas em suas vidas e nas vidas de seus filhos e familiares.

\subsection{Explanação dos dados quantitativos e qualitativos}

Os resultados obtidos nas duas etapas da pesquisa sugerem que existe uma diferença entre as avaliações recebidas na plataforma REDCap por meio de um instrumento estruturado e os comentários livres registrados nas mídias sociais.

As avaliações coletadas pela plataforma tecnológica empregando questionário estruturado possui menos adesão da população, porém são mais detalhadas por se guiarem por um instrumento formal. A análise dos dados quantitativos demonstra, por exemplo, que a 
população julga relevante receber informação em saúde e que a linguagem empregada é apropriada para a adequada compreensão da evidência em saúde. Foram identificados por meio deste processo de avaliação outros usos para as evidências disseminadas, como uso em trabalhos escolares e atividades profissionais não necessariamente ligadas à área da saúde.

A análise dos dados qualitativos demonstra que a população não aceita a evidência com passividade, questionando e comparando a informação recebida com sua experiência de vida e com suas observações da realidade. Percebeu-se ainda que, nas mídias sociais, a população, por não ter outros instrumentos, avalia as evidências dicotomicamente, por concordância ou discordância, a partir de seu conhecimento empírico. Outro aspecto observado na análise qualitativa é que a disseminação de evidências nas mídias sociais promove, em algumas situações, um diálogo, no qual alguns comentários provocam réplicas e tréplicas, algo que não acontece nas avaliações por meio do questionário estruturado. Assim, a disseminação das evidências nas mídias sociais parece promover um debate e uma construção colaborativa sobre a evidência.

Nas duas etapas da pesquisa, observou-se que as mulheres são as que mais avaliaram as evidências disseminadas, sendo $100 \%$ nas mídias sociais e $77,4 \%$ por meio da enquete na Plataforma REDCap.

\section{CONCLUSÃO}

Este estudo abordou duas possibilidades de avaliação de evidências em saúde pela população. Percebeu-se que a população se sente mais à vontade para criticar as informações diretamente nas mídias sociais por meio de comentários livres que acessar um link para responder a um questionário estruturado. É compreensível que a população tenha esse comportamento, já que o fator tempo pode interferir nesta ação. Porém, as avaliações obtidas por um instrumento formal fornecem dados também significativos para verificar o impacto de cada evidência disseminada. Assim, entende-se que apenas os comentários registrados nas mídias sociais são insuficientes para a adequada avaliação da evidência.

Adicionalmente, observou-se que, tanto nas mídias sociais como no questionário estruturado, o público que mais avalia a informação são as mulheres. Fica o desafio de fazer com que as evidências em saúde sejam avaliadas por outros segmentos da população, preferencialmente empregando instrumentos formais de avaliação. Imagina-se que ações e temáticas mais direcionadas a outros públicos poderão motivar novas avaliações, mas isto será tema de estudo futuro deste grupo de pesquisadores. 


\section{AGRADECIMENTOS}

Os autores agradecem a Universidade de São Paulo por ter concedido bolsas para os seguintes alunos participantes deste projeto: Nivaldo Sena da Silva, Cláudio Vinícius de Assis Rondado, Gabriella Neves Cury, Lenisa de Mello e Souza, Gustavo José Miranda da Cunha, Jéssica Nara Targino Cavalcante, Larissa Oliveira Almeida e Ângelo Alves Favaro.

Os autores agradecem aos professores Prof. Dr. Pierre Pluye e Prof. Roland Grad da Faculdade de Medicina da McGill University por autorizarem a tradução e o uso do instrumento IAM4All neste projeto. Agradecimentos também ficam registrados aos profissionais de saúde que colaboraram com a elaboração ou revisão de algumas evidências disseminadas pelo projeto, quais sejam: Enf. Cristina Camargo Dalri, Enf. Iara Pedro, Dr. Fábio Volpe e Dr. Mateus Andrea Angelucci.

\section{REFERENCIAS}

BENEDICTA, B.; CALDWELL, P.H.Y.; SCOTT, K.M. How parents use, search for and appraise online health information on their child's medical condition: a pilot study. Journal of Paediatrics and Child Health, Wiley, ed. cont., p.1-5, jul. 2019. https://doi.org/10.1111/jpc. 14575

CENTRE for Evidence-Based Medicine. OCEBM Levels of Evidence. Oxford: University of Oxford, 2016. Disponível em: https://www.cebm.net/2016/05/ocebm-levels-of-evidence/ . Acesso em: 14 set. 2019.

FREEMAN, Jaimie L. et al. How adolescents search for and appraise online health information: a systematic review. Journal of Pediatrics, [s.1.], v. 195, p. 244- 255, 2018.

GALVAO, M. C. B. et al. The Clinical Relevance of Information Index (CRII): assessing the relevance of health information to the clinical practice. Health Information \& Libraries Journal, Wiley, v. 30, n. 2, p. 110-120, jun. 2013. Disponível em: https://onlinelibrary.wiley.com/doi/full/10.1111/hir.12021 Acesso em: 14 set. 2019.

GALVAO, M.C.B.; PLUYE, P.; RICARTE, I.L.M. Métodos de pesquisa mistos e revisões de literatura mistas: conceitos, construção e critérios de avaliação. InCID: Revista de Ciência da Informação e Documentação, São Paulo, v. 8, n. 2, p. 4-24, 2017. Disponível em: https://www.revistas.usp.br/incid/article/view/121879 . Acesso em: 2 set. 2019.

HARRIS, Paul A. et al. The REDCap consortium: Building an international community of software platform partners. Journal of Biomedical Informatics, [s.1.], v. 95, p. 103208, Dec. 2018.

HAYNES, R.B. et al. Second-order peer review of the medical literature for clinical practitioners. Journal of the American Medical Association, [s.1.], v. 295, n. 15, p. 18011808, 2006. 
INTERNATIONAL Federation of Library Associations. Development and Access to Information. Den Haag: IFLA, 2017. Disponível em:

https://da2i.ifla.org/sites/da2i.ifla.org/files/uploads/docs/da2i-2017-chapter4.pdf. Acesso em: 11 set. 2019.

JOHNSON, R.B.; ONWUEGBUZIE, A.J.; TURNER, L.A. Toward a definition of mixed methods research. Journal of Mixed Methods Research, [s.1.], v. 1, n. 2, p.112-133, 2007.

KIM, H.; CHOI, B. A comparative examination of factors that affect the credibility of health information on social media. Proceedings of the Association for Information Science and Technology, [s.1.], v. 55, n. 1, p. 843-844, 2018.

MOON, R.Y. et al. Mothers' Perceptions of the Internet and social media as sources of parenting and health information: qualitative study. Journal of Medical Internet Research, [s.1.], v. 21, n. 7, p. e14289, 2019.

PLUYE, P. et al. Number needed to benefit from information (NNBI): Proposal from a mixed methods research study with practicing family physicians. Annals of Family Medicine, [s.1.], v. 11, n. 6 , p. 559-567, 2013.

PLUYE, P. Les méthodes mixtes. In: RIDDE, V.; DAGENAIS, C. (ed.). Approches et pratiques en évaluation de programme. Montréal: Presses de l'Université de Montréal, 2012. p. 125-143.

PLUYE, Pierre et al. Development and content validation of the information assessment method for patients and consumers. JMIR research protocols, [s.1.], v. 3, n. 1, p. e7, jan. 2014.

SBAFFI, Laura; ROWLEY, Jennifer. Trust and credibility in web-based health information: A review and agenda for future research. Journal of Medical Internet Research, [s.1.], v. 19, n. $6,2017$.

STABLEFORD, S.; METTGER, W. Plain language: A Strategic Response to the Health Literacy Challenge. Journal of Public Health Policy, [s.1.], v. 28, n. 1, p. 71-93, 2016.

UNITED States. Plain language definition. US, s.d. Disponível em:

https://www.plainlanguage.gov/about/definitions/. Acesso em: 11 set. 2019.

WORLD Health Organization. Health literacy. Geneva: WHO, 2019. Disponível em: https://www.who.int/healthpromotion/health-literacy/en/. Acesso em: 14 set. 2019.

WORLD Health Organization. International Telecommunication Union. National e-Health strategy toolkit. Geneva: WHO, 2012. Disponível em: https://www.itu.int/dms_pub/itud/opb/str/D-STR-E_HEALTH.05-2012-PDF-E.pdf. Acesso em: 11 set. 2019. 